\title{
A hospital stay - the children's view
}

\author{
Alexander Avian ${ }^{1 *}$, Brigitte Messerer ${ }^{2}$, Sebastian Diem ${ }^{1}$, Andrea Berghold ${ }^{1}$, Andreas Sandner-Kiesling ${ }^{2}$, \\ Annelie Weinberg ${ }^{3}$
}

From Safety in hospitals: from strategy to implementation Annual Scientific Meeting 2015

Graz, Austria. 29-30 September 2015

\section{Background}

Regular pain assessment and documentation of side effect are important factors for successful pain management [1]. Therefore pain assessment is very common in hospitals. Other factors also important for patients and also influencing pain intensity are assessed seldomly. These factors, like perioperative anxiety [2] or sleep [3] may also influence pain perception.

\section{Material and methods}

In a prospective, exploratory pilot study structured interviews were conducted with 48 children and adolescents (mean age: 13.1, range: 11 - 17; female: $35 \%$ ) to evaluate their view of the hospital stay. To identify potential areas for improvement the main focus of these interviews was to record patient's complaints. Therefore patients were encouraged to tell how they experienced their hospital stay, how they felt and to tell how they slept in the hospital. In order to get an unbiased view, patients were not asked specific questions regarding their wellbeing, sleep or other topics.

\section{Results}

Forty out of $48(83 \%)$ children and adolescents reported some kind of reduced well-being. The most frequent complaints were boredom (46\%), followed by fear (40\%) and nervousness (31\%). A similar number of children and adolescents (85\%) reported sleep related problems. The most frequent sleep related complaints were tiredness during the day (48\%) and disturbance of sleep caused by pain $(38 \%)$ or medical care $(33 \%)$. While only 20 out of $48(42 \%)$ children and adolescent reported nausea or vomiting additional eleven patients $(23 \%)$ reported dizziness.

\section{Conclusions}

Beside the common aspects like PONV, other complaints like tiredness, sleep disturbance and fear are experienced in many patients. These aspects may affect pain perception and should be therefore evaluated. Furthermore, usage of age specific phrases like dizziness additional to nausea should be considered.

\section{Competing interests}

Supported by funds of the Oesterreichische Nationalbank (Oesterreichische Nationalbank, Anniversary Fund, project number: 14335) and the State of Styria (GZ: Abt.08-16.M-1/2012-39)

\section{Authors' details}

${ }^{1}$ Institute for Medical Informatics, Statistics and Documentation, Medical University of Graz, Austria. ${ }^{2}$ Department of Anesthesiology and Intensive Care Medicine, Medical University of Graz, Austria. ${ }^{3}$ Department of

Orthopedic Surgery, Medical University of Graz, Austria.

Published: 30 October 2015

\section{References}

1. Messerer B, Gutmann A, Weinberg A, Sandner-Kiesling A: Implementation of a standardized pain management in a pediatric surgery unit. Pediatr Surg Int 2010, 26:879-889.

2. Chieng YJS, Chan ACS, Klainin-Yobas P, He H-G: Perioperative anxiety and postoperative pain in children and adolescents undergoing elective surgical procedures: a quantitative systematic review. J Adv Nurs 2014, 70:243-255.

3. Lewin DS, Dahl RE: Importance of sleep in the management of pediatric pain. J Dev Behav Pediatr 1999, 20:244-252.

doi:10.1186/2056-5917-1-S1-A1

Cite this article as: Avian et al:: A hospital stay - the children's view. Safety in Health 2015 1(Suppl 1):A1.

\footnotetext{
* Correspondence: alexander.avian@medunigraz.at

${ }^{1}$ Institute for Medical Informatics, Statistics and Documentation, Medical

University of Graz, Austria

Full list of author information is available at the end of the article
}

C 2015 Avian et al. This is an Open Access article distributed under the terms of the Creative Commons Attribution License (http:// creativecommons.org/licenses/by/4.0), which permits unrestricted use, distribution, and reproduction in any medium, provided the original work is properly cited. The Creative Commons Public Domain Dedication waiver (http://creativecommons.org/publicdomain/ zero/1.0/) applies to the data made available in this article, unless otherwise stated. 